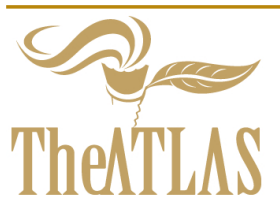

\title{
Methodology of Transdisciplinarity-Levels of Reality, Logic of the Included Middle and Complexity
}

Basarab Nicolescu, International Center for Transdisciplinary Research and Studies (CIRET), France, Email: nicol@club-internet.fr

doi: $10.22545 / 2010 / 0009$

T he concept of levels of Reality, formulated in 1982, is the key concept of transdisciplinarity ${ }^{1}$. The introduction of the levels of Reality induces a multidimensional and multi-referential structure of Reality, signifying the coexistence between complex plurality and open unity. Every level is characterized by its incompleteness; the laws governing this level are just a part of the totality of laws governing all levels. And even the totality of laws does not exhaust the entire Reality; we have also to consider the interaction between Subject and Object. The zone between two different levels and beyond all levels is a zone of non-resistance to our experiences, representations, descriptions, images, and mathematical formulations. The Gdelian structure of levels of Reality implies the impossibility of a selfenclosed complete theory. Knowledge is forever open. The unity of levels of Reality of the Object and its complementary zone of non-resistance defines the transdisciplinary Object. The unity of levels of Reality of the Subject and this complementary zone of non-resistance defines the transdisciplinary Subject. The zone of non-resistance plays the role of a third between the Subject and the Object, an in-

${ }^{1} 1$ Apostel et al., 1972. teraction term which allows the unification of the transdisciplinary Subject and the transdisciplinary Object. This interaction term is called the Hidden Third. The ternary partition (Subject, Object, Hidden Third) is, of course, radically different from the binary partition (Subject vs. Object) of classical realism..

Keywords: reality, levels, transdisciplinarity, classical realism, quantum realism, logic of the included middle, complexity, disciplinary boundaries, spirituality, homo economicus, homo religiosus.

\section{The War of Defination}

\subsection{How Transdisciplinarity was Born}

Transdisciplinarity is a relatively young approach; Swiss philosopher and psychologist Jean Piaget (1896-1980) developed the concept seven centuries after disciplinarity had evolved. The word itself first appeared in France, in 1970, in the talks of Jean Piaget, Erich Jantsch, and Andr Lichnerowicz at the international workshop "Interdisciplinarity - Teaching and Research Problems in Universities," organized by the Organization for Economic Cooperation and Development (OECD) in collabora- 
tion with the French Ministry of National Education and University of Nice ${ }^{1}$.

In his contribution, Piaget gives the following description of transdisciplinarity: "Finally, we hope to see succeeding to the stage of interdisciplinary relations a superior stage, which should be 'transdisciplinary,' i.e. which will not be limited to recognize the interactions and/or reciprocities between the specialized researches, but which will locate these links inside a total system without stable boundaries between the disciplines." ${ }^{2}$ While this description is vague, it has the merit of pointing to a new space of knowledge "without stable boundaries between the disciplines." However, the idea of a "total system" opens the trap of transforming transdisciplinarity into a super- or hyperdiscipline, a kind of "science of sciences." In other words, the description of Piaget leads to a closed system, in contradiction with his own requirement of the instability of boundaries between disciplines. The key point here is the fact that Piaget retained only the meanings "across" and "between" from the Latin prefix trans, eliminating the meaning "beyond." Understood in such a way, transdisciplinarity is just a new, "superior stage of interdisciplinarity. I think Piaget was fully conscious of this alteration of transdisciplinarity, but the intellectual climate was not yet prepared for receiving the shock of contemplating the possibility of a space of knowledge beyond the disciplines. The proof is that in his introduction to the Proceedings of the workshop, Pierre Duguet honestly recognized that some experts wanted to see the word" transdisciplinarity in the title of the workshop, but authorities of the OECD refused to do so because they were afraid to confuse some representatives of the member countries ${ }^{3}$.

In his contributions, Erich Jantsch, an Austrian thinker living in California, falls in the trap of defining transdisciplinarity as a hyperdiscipline. He writes that transdisciplinarity is "the coordination of all disciplines and interdisciplines of the teaching system and the innovation on the basis of a general axiomatic approach." ${ }^{4}$ He clearly situates transdisciplinarity in the disciplinary framework. However, the historical merit of Jantsch was to underscore the necessity of inventing an axiomatic approach for

\footnotetext{
${ }^{2}$ Piaget, 1972, p. 144 .

${ }^{3}$ Duguet, 1972 , p. 13.

${ }^{4}$ Jantsch, 1972 a, p. 108. The same ideas are expressed in Jantsch, 1972 b.
}

transdisciplinarity and also of introducing values in this field of knowledge.

Finally, the approach of André Lichnerowicz, a known French mathematician, is radically mathematical. He sees transdisciplinarity as a transversal play to describe "the homogeneity of the theoretical activity in different sciences and techniques, independently of the field where this activity is effectuated." 5 And, of course, this theoretical activity can be formulated, he thinks, only in mathematical language. Lichnerowicz writes: "The Being is put between parentheses, and it is precisely this non-ontological character which confers to mathematics its power, its fidelity, and its polyvalence." ${ }^{6}$ The interest of Lichnerowicz for transdisciplinarity was accidental, but his remark about the non-ontological character of mathematics has to be remembered.

I described in some detail the three different positions of Piaget, Jantsch, and Lichnerowicz concerning transdisciplinarity because they can be found again, a quarter of a century later, in what I call "the war of definitions." The word "war" does not belong in the transdisciplinary vocabulary. However, I use it purposely because it appeared in the issue "Guerre et paix entre les sciences: disciplinaritét transdisciplinarité / War and Peace Between Sciences: Disciplinarity and Transdisciplinarity" 7 of a French magazine. In this issue, one of the authors asked for the interdiction of the word "transdisciplinarity." 7 His desire was obviously not satisfied.

would like to add to this discussion about the incipient phase of transdisciplinarity the name of Edgar Morin. A short time after the Nice meeting, Morin begins to use the word "transdisciplinarity," and he even leads a transdisciplinary laboratory in human sciences within the framework of a prestigious French research institution. It is true that Morin did not give a definition of transdisciplinarity. For him, transdisciplinarity was, in that period, a kind of messenger of the freedom of thinking, a go-between discipline.

\subsection{Beyond Disciplines}

I proposed the inclusion of the meaning "beyond disciplines" in $1985^{8}$ and have since developed this idea over the years in articles, books, and various

\footnotetext{
${ }^{5}$ 5Lichnerowicz, 1972, pp. 130-131.

${ }^{6}$ 6Ibid., pp. 127.

${ }^{7}$ Alain Caill, in Guerre,, 1996.

${ }^{8} \mathrm{Nicolescu,} 1985$.
} 
official international documents. Many other researchers over the world contributed to this development of transdisciplinarity. A key date in this development is 1994, when the Charter of Transdisciplinarity ${ }^{9}$ was adopted by the participants at the First World Congress of Transdisciplinarity (Convento da Arrbida, Portugal). This idea did not come from heaven or just from the pleasure of respecting the etymology of the word trans but from my long practice of quantum physics. For an outsider, it might seem paradoxical that it is from the very core of exact sciences that we arrive at the idea of limits of disciplinary knowledge. But from within, it provides evidence of the fact that, after a very long period, disciplinary knowledge has reached its own limitations with far-reaching consequences not only for science but also for culture and social life.

The crucial point here is the status of the Subject.

Modern science was born through a violent break with the ancient vision of the world. It was founded on the idea-surprising and revolutionary for that era - of a total separation between the knowing subject and Reality, which was assumed to be completely independent from the subject who observed it. This break allowed science to develop independently of theology, philosophy, and culture. It was a positive act of freedom. But today, the extreme consequences of this break, incarnated by the ideology of scientism, pose the potential danger of self-destruction of our species.

On the spiritual level, the consequences of scientism have been considerable: the only knowledge worthy of its name must therefore be scientific, objective; the only reality worthy of this name must be, of course, objective reality, ruled by objective laws. All knowledge other than scientific knowledge is thus cast into the inferno of subjectivity, tolerated at most as a meaningless embellishment or rejected with contempt as a fantasy, an illusion, a regression, or a product of the imagination. Even the word "spirituality" has become suspect and its use has been practically abandoned.

Objectivity, set up as the supreme criterion of Truth, has one inevitable consequence: the transformation of the Subject into an Object. The death of the Subject is the price we pay for objective knowledge. The human being became an object - an object of the exploitation of man by man; an object of the experiments of ideologies that are proclaimed scien-

\footnotetext{
9 "Charter."
}

tific; an object of scientific studies to be dissected, formalized, and manipulated. The Man - God has become a Man - Object, of which the only result can be self-destruction. The two world massacres of this century, not to mention the multiple local wars and terrorism, are only the prelude to self-destruction on a global scale.

In fact, with very few exceptions - Husserl, Heidegger, Gadamer, or Cassirer, for example - modern and post-modern thinkers gradually transformed the Subject in a grammatical subject. The Subject is today just a word in a phrase ${ }^{10}$.

The quantum revolution radically changed this situation. The new scientific and philosophical notions it introduced - the principle of superposition of quantum "yes" and "no" states, discontinuity, nonseparability, global causality, quantum indeterminism - necessarily led the founders of quantum mechanics to rethink the problem of the complete Object/Subject separation. For example, Werner Heisenberg, Nobel Prize winner of Physics, thought that one must suppress any rigid distinction between the Subject and Object, between objective reality and subjective reality. "The concept of 'objective and 'subjective,'" writes Heisenberg, "designate[s] two different aspects of one reality; however we would make a very crude simplification if we want to divide the world in[to] one objective reality and one subjective reality. Many rigidities of the philosophy of the last centuries are born by this black and white view of the world." 11 Heisenberg also asserts that we have to renounce the privileged reference to the exteriority of the material world. "The too strong insistence on the difference between scientific knowledge and artistic knowledge comes from the wrong idea that concepts describe perfectly the 'real things.' [...] All true philosophy is situated on the threshold between science and poetry." 12

My line of thinking is in perfect agreement with that of Heisenberg. For me, "beyond disciplines" precisely signifies the Subject, and, more precisely, the Subject-Object interaction. The transcendence inherent in transdisciplinarity is the transcendence of the Subject. The Subject cannot be captured in a disciplinary camp.

The meaning "beyond disciplines" leads us to an immense space of new knowledge. The main

\footnotetext{
${ }^{10}$ Descombes, 2004.

${ }^{11}$ Heisenberg, 1998, p. 269.

${ }^{12}$ Idem, pp. 363-364.
} 
outcome was the formulation of the methodology of transdisciplinarity, which I will analyze in the next section. It allows us also to clearly distinguish between multidisciplinarity, interdisciplinarity, and transdisciplinarity.

Multidisciplinarity concerns itself with studying a research topic in not just one discipline but in several simultanously. From this perspective, any topic will ultimately be enriched by incorporating the perspectives of several disciplines. Multidisciplinarity brings a plus to the discipline in question, but this plus is always in the exclusive service of the home discipline. In other words, the multidisciplinary approach overflows disciplinary boundaries while its goal remains limited to the framework of disciplinary research.

Interdisciplinarity has a different goal than multidisciplinarity. It concerns the transfer of methods from one discipline to another. Like multidisciplinarity, interdisciplinarity overflows the disciplines, but its goal still remains within the framework of disciplinary research. Interdisciplinarity even has the capacity of generating new disciplines, such as quantum cosmology and chaos theory.

Transdisciplinarity concerns that which is at once between the disciplines, across the different disciplines, and beyond all disciplines. Its goal is the understanding of the present world, of which one of the imperatives is the unity of knowledge ${ }^{13}$.

As one can see, there is no opposition between disciplinarity (including multidisciplinarity and interdisciplinarity) and transdisciplinarity, but there is instead a fertile complementarity. In fact, there is no transdisciplinarity without disciplinarity. In spite of this fact, the above considerations provoked, around 1990, a more or less violent war of definitions This war is not yet finished.

There is a specific different approach of transdisciplinarity that is characterized by the refusal of formulating any methodology and by its exclusive concentration on joint problem-solving of problems pertaining to the science-technology-society triad. This approach is represented by figures like Michael Gibbons ${ }^{14}$ and Helga Nowotny ${ }^{15}$. The point of view of this transdisciplinary current was largely expressed at the Zürich Congress, held in the year

${ }^{13}$ Nicolescu, 1996

${ }^{14}$ Gibbons, 1994.

${ }^{15}$ Nowotny, 1994 and "The Potential of Transdisciplinarity".
$2000^{16}$.

This version of transdisciplinarity does not exclude the meaning "beyond disciplines" but reduces it to the interaction of disciplines with social constraints. The social field necessarily introduces a dimension "beyond disciplines," but the individual human being is conceived of as part of a social system only. The spiritual dimension is therefore absent in this approach.

It is difficult for us to understand why "joint problem solving" must be the unique aim of transdisciplinarity. It is certainly one of the important aims but not the only aim. The use of such a narrow characterization seems to us dangerous, as in religion, allowing unnecessary wars and unproductive dogmatism. Is transdisciplinarity concerning only society as a uniform whole, or, the human being who is (or has to be) in the center of any civilized society? Are we allowed to identify knowledge with production of knowledge? Why does the potential of transdisciplinarity have to be reduced to produce "better science"? Why does transdisciplinarity have to be reduced to "hard science"? In other words, the Subject-Object interaction seems to us to be at the very core of transdisciplinarity and not the Object alone.

I think the unconscious barrier to a true dialogue comes from the inability of certain transdisciplinary researchers to think about discontinuity. I will give an image in order to express what I have in mind. For them, the boundaries between disciplines are like boundaries between countries, continents, and oceans on the surface of the Earth. These boundaries are fluctuating in time, but a fact remains unchanged: the continuity between territories. We have a different approach of the boundaries between disciplines. For us, they are like the separation between galaxies, solar systems, stars, and planets. It is the movement itself that generates the fluctuation of boundaries. This does not mean that a galaxy intersects another galaxy. When we cross the boundaries, we meet the interplanetary and intergalactic vacuum. This vacuum is far from being empty; it is full of invisible matter and energy. It introduces a clear discontinuity between territories of galaxies, solar systems, stars, and planets. Without the interplanetary and intergalactic vacuum, there is no Universe.

It is my deep conviction that our formulation of

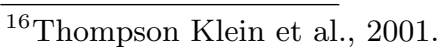


transdisciplinarity is both unified (in the sense of unification of different transdisciplinary approaches) and diverse: unity in diversity and diversity through unity is inherent to transdisciplinarity. Much confusion arises by failing to recognize that there is a theoretical transdisciplinarity, aphenomenological transdisciplinarity, and an experimental transdisciplinarity.

The word theory implies a general definition of transdisciplinarity and a well - defined methodology (which has to be distinguished from "methods"; a single methodology corresponds to a great number of different methods). The word phenomenology implies building models that connect the theoretical principles with the already observed experimental data in order to predict further results. The word experimental implies performing experiments following a well-defined procedure, allowing any researcher to get the same results when performing the same experiments.

I classify the work done by Michael Gibbons and Helga Nowotny as phenomenological transdisciplinarity, while I define my own work ${ }^{17}$, as well as that of Jean Piaget and Edgar Morin ${ }^{18}$, as theoretical transdisciplinarity. In its turn, experimental transdisciplinarity concerns a large number of experimental data already collected not only in the framework of knowledge production but also in fields such as education, psychoanalysis, the treatment of pain in terminal diseases, drug addiction, art, literature, history of religions, etc. The reduction of transdisciplinarity to only one of its aspects is very dangerous because it will transform transdisciplinarity into a temporary fashion, which I predict will disappear soon just as many other fashions in the field of culture and knowledge have indeed vanished. The huge potential of transdisciplinarity will never be accomplished if we do not accept the simultaneous and rigorous consideration of the three aspects of transdisciplinarity. This simultaneous consideration of theoretical, phenomenological, and experimental transdisciplinarity will allow both a unified and nondogmatic treatment of the transdisciplinary theory and practice, coexisting with a plurality of transdisciplinary models. ATLAS seems to me an ideal place to practice all three aspects of transdisciplinarity in a fruitful manner.

\footnotetext{
${ }^{17}$ Nicolescu, 1985, 1986, 1991, 1996, 1998, 2000, 2002, 20042009.

${ }^{18}$ Morin, 1999.
}

\section{Formulation of the methodology of Transdisciplinarity}

\subsection{The Axiomatic Character of the Methodology of Transdisciplinarity}

The most important achievement of transdisciplinarity in present times is, of course, the formulation of the methodology of transdisciplinarity, accepted and applied by an important number of researchers in many countries around the world. In the absence of a methodology, transdisciplinarity would be just talking, an empty discourse and therefore a shortterm living fashion. The axiomatic character of the methodology of transdisciplinarity is an important aspect. This means that we have to limit the number of axioms (or principles or pillars) to a minimum number. Any axiom that can be derived from the already postulated ones would have to be rejected. This fact is not new. It already happened when disciplinary knowledge acquired its scientific character due the three axioms formulated by Galileo Galilei in Dialogue on the Great World Systems ${ }^{19}$ :

1. There are universal laws, of a mathematical character.

2. These laws can be discovered by scientific experiment.

3. Such experiments can be perfectly replicated.

It should be obvious that if we try to build a mathematical bridge between science and ontology, we will necessarily fail. Galileo himself makes the distinction between human mathematics and divine mathematics ${ }^{20}$. Human mathematics constitutes, he says (via Salvati), the common language of human beings and God, while divine mathematics is connected with the direct perception of the totality of all existing laws and phenomena. Transdisciplinarity tries to seriously take this distinction into account. A bridge can be built between science and ontology only by taking into account the totality of human knowledge. This requires a symbolic language, different from mathematical language and enriched by specific new notions. Mathematics is able to describe repetition of facts due to scientific laws, but transdisciplinarity is about the singularity of the human being and human life. The key point here is, once

\footnotetext{
${ }^{19}$ 19Galileo, 1956, 1992.

${ }^{20}$ Galileo, 1992, p. 192.
} 
again, the irreducible presence of the Subject, which explains why transdisciplinarity cannot be described by a mathematical formalism. The dream of the mathematical formalization of transdisciplinarity is just a phantasm, the phantasm induced by centuries of disciplinary knowledge.

After many years of research, we have arrived ${ }^{21}$ at the following three axioms of the methodology of transdisciplinarity:

1. The ontological axiom: There are, in Nature and society and in our knowledge of Nature and society, different levels of Reality of the Object and, correspondingly, different levels of Reality of the Subject.

2. The logical axiom: The passage from one level of Reality to another is ensured by the logic of the included middle.

3. The complexity axiom: The structure of the totality of levels of Reality or perception is a complex structure: every level is what it is because all the levels exist at the same time.

The first two get their experimental evidence from quantum physics, but they go well beyond exact sciences. The last one has its source not only in quantum physics but also in a variety of other exact and human sciences. All three are in agreement with traditional thinking present on the earth since the beginning of historical times.

Axioms cannot be demonstrated; they are not theorems. They have their roots in experimental data and theoretical approaches, and their validity is judged by the results of their applications. If the results are in contradiction with experimental facts, they have to be modified or replaced.

Let me note that, in spite of an almost infinite diversity of methods, theories, and models that run throughout the history of different scientific disciplines, the three methodological postulates of modern science have remained unchanged from Galileo. Let us hope that the same will prove to be true for transdisciplinarity and that a large number of transdisciplinary methods, theories, and models will appear in the future.

Let me also note that only one science has entirely and integrally satisfied the three Galilean postulates: physics. The other scientific disciplines only partially satisfy the three methodological postulates of

${ }^{21}$ Nicolescu, 1996. modern science. However, the absence of rigorous mathematical formulation in psychology, psychoanalysis, history of religions, law theory, and a multitude of other disciplines did not lead to the elimination of these disciplines from the field of science. At least for the moment, not even an exact science like molecular biology can claim a mathematical formulation as rigorous as that of physics. In other words, there are degrees of disciplinarity which can more or less completely take into account the three methodological postulates of modern science. Likewise, the process of more or less taking completely into account the three methodological pillars of transdisciplinary research will generate different degrees of transdisciplinarity. Large avenues are open for a rich and diverse transdisciplinary research.

The above three axioms give a precise and rigorous definition of transdisciplinarity. This definition is in agreement with the one sketched by Jean Piaget.

Let me now describe the essentials of these three transdisciplinary axioms.

\subsection{The Ontological Axiom: Levels of Reality and Levels of Perception}

The key concept of the transdisciplinary approach to Nature and knowledge is the concept of levels of Reality.

Here, the meaning we give to the word "Reality" is pragmatic and ontological at the same time. By "Reality," we intend first of all to designate that which resists our experiences, representations, descriptions, images, or even mathematical formulations.

Insofar as Nature participates in the being of the world, one has to assign also an ontological dimension to the concept of Reality. Reality is not merely a social construction, the consensus of a collectivity, or some inter-subjective agreement. It also has a trans - subjective dimension; for example, experimental data can ruin the most beautiful scientific theory.

Of course, one has to distinguish the words "Real" and "Reality." Real designates that which is, while Reality is connected to resistance in our human experience. The "Real" is, by definition, veiled forever, while "Reality" is accessible to our knowledge.

By "level of Reality," I designate a set of systems that are invariant under certain laws. For example, quantum entities are subordinate to quantum laws, which depart radically from the laws of the macrophysical world. That is to say that two levels of Reality are different if, while passing from one to 
the other, there is a break in the applicable laws and a break in fundamental concepts (like, for example, causality). Therefore there is a discontinuity in the structure of levels of Reality, similar to the discontinuity reigning over the quantum world.

Every level of Reality has its associated spacetime, different from one level to the other. For example, the classical realism is associated with the 4-dimensional space-time (three dimensions of space and one dimension of time), while the quantum realism is associated with a space-time whose number of dimensions is greater than four. The introduction of the levels of Reality induces a multidimensional and multireferential structure of Reality.

A new Principle of Relativity ${ }^{22}$ emerges from the coexistence between complex plurality and open unity in our approach: no level of Reality constitutes a privileged place from which one is able to understand all the other levels of Reality. A level of Reality is what it is because all the other levels exist at the same time. This Principle of Relativity is what originates a new perspective on religion, politics, art, education, and social life. And when our perspective on the world changes, the world changes. The great Brazilian educator Paulo Freire asserts in his Pedagogy of the Oppressed ${ }^{23}$ that saying a true word is equivalent to the transformation of the world.

In other words, our approach is not hierarchical. There is no fundamental level. But its absence does not mean an anarchical dynamic but a coherent one of all levels of Reality, both those already discovered and those that will be discovered in the future.

Every level is characterized by its incompleteness: the laws governing this level are just a part of the totality of laws governing all levels. And even the totality of laws does not exhaust the entire Reality; we have also to consider the Subject and its interaction with the Object.

The zone between two different levels and beyond all levels is a zone of non-resistance to our experiences, representations, descriptions, images, and mathematical formulations. Quite simply, the transparence of this zone is due to the limitations of our bodies and of our sense organs - limitations that apply regardless of what measuring tools are used to extend these sense organs. We therefore have to conclude that the topological distance between levels

\footnotetext{
${ }^{22}$ Nicolescu, 1996, pp. 54-55.

${ }^{23}$ Freire, 1968.
}

is finite. However, this finite distance does not mean a finite knowledge. Take a segment of a straight line - it contains an infinite number of points. In a similar manner, a finite topological distance could contain an infinite number of levels of Reality. We have work to do till the end of time.

This open structure of the unity of levels of Reality is in accord with one of the most important scientific results of the twentieth century concerning arithmetic, the theorem of Kurt Gödel, which states that a sufficiently rich system of axioms inevitably leads to results that are either undecidable or contradictory. The implications of Gödel's ${ }^{24}$ theorem have considerable importance for all modern theories of knowledge, primarily because it concerns not just the field of arithmetic but all of mathematics that include arithmetic. The Gödelian structure of levels of Reality implies the impossibility of a self - enclosed, complete theory. Knowledge is forever open.

The zone of non-resistance corresponds to the sacred - to that which does not submit to any rationalization. Proclaiming that there is a single level of Reality eliminates the sacred, and self-destruction is generated.

The unity of levels of Reality and its complementary zone of non-resistance constitutes what we call the transdisciplinary Object.

Inspired by the phenomenology of Edmund Husserl $^{25}$, I assert that the different levels of Reality of the Object are accessible to our knowledge thanks to the different levels of Reality of the Subject. They permit an increasingly general, unifying, encompassing vision of Reality without ever entirely exhausting it.

As in the case of levels of Reality of the Object, the coherence of levels of Reality of the Subject presupposes a zone of non-resistance to perception.

The unity of levels of Reality of the Subject and this complementary zone of non-resistance constitutes what we call the transdisciplinary Subject.

The two zones of non-resistance of transdisciplinary Object and Subject must be identical for the transdisciplinary Subject to communicate with the transdisciplinary Object. A flow of consciousness that coherently cuts across different levels of perception must correspond to the flow of information coherently cutting across different levels of Reality.

\footnotetext{
${ }^{24}$ Nagel and Newman, 1958

${ }^{25}$ Husserl, 1966.
} 
The two flows are interrelated because they share the same zone of non-resistance.

Knowledge is neither exterior nor interior; it is simultaneously exterior and interior. The studies of the universe and of the human being sustain one another. Without spirituality, the knowledge is a dead knowledge.

The zone of non-resistance plays the role of a third between the Subject and the Object, an Interaction term, which acts like a secretly included middle that allows for the unification of the transdisciplinary Subject and the transdisciplinary Object while preserving their difference. I will call this Interaction term the Hidden Third.

Our ternary partition (Subject, Object, Hidden Third) is, of course, different from the binary partition (Subject vs. Object) of classical realism.

The emergence of at least three different levels of Reality in the study of natural systems - the macrophysical level, the microphysical level, and the cyber - space - time (to which one might add a fourth level, that of superstrings, unifying all physical interactions) - is a major event in the history of knowledge. Based upon our definition of levels of Reality, we can identify other levels than just the ones in natural systems. For example, in social systems, we can speak about the individual level, the geographical and historical community level (family, nation), the cyber-space-time community level, and the planetary level.

Levels of Reality are radically different from levels of organization as these have been defined in systemic approaches ${ }^{26}$. Levels of organization do not presuppose a discontinuity in the fundamental concepts; several levels of organization can appear at the same level of Reality. The levels of organization correspond to different structures of the same fundamental laws.

The levels of Reality and the levels of organization offer the possibility of a new taxonomy of the more than 8000 academic disciplines existing today. Many disciplines coexist at the same level of Reality even if they correspond to different levels of organization. For example, Marxist economy and classical physics belong to one level of Reality, while quantum physics and psychoanalysis belong to another level of Reality.

The existence of different levels of Reality has been affirmed by different traditions and civilizations, but this affirmation was founded either on religious

${ }^{26}$ Camus et al., 1998. dogma or on the exploration of the interior universe only.

The transdisciplinary Object and its levels of Reality, the transdisciplinary Subject and its levels of perception, and the Hidden Third define the transdisciplinary model of Reality. Based on this ternary structure of Reality, we can deduce other ternaries of levels that are extremely useful in the analysis of concrete situations by contextualization:

Levels of organization-Levels of structuring -Levels of integration

Levels of confusion-Levels of language -Levels of interpretation

Physical levels-Biological levels-Psychical levels

Levels of ignorance-Levels of intelligence -Levels of contemplation

Levels of objectivity-Levels of subjectivity -Levels of complexity

Levels of knowledge-Levels of understanding -Levels of being

Levels of materiality-Levels of spirituality -Levels of non-duality

I formulated the idea of levels of Reality in 1976 during a post-doctoral stay at the Lawrence Berkeley Laboratory following stimulating discussions with Geoffrey Chew, the founder of the bootstrap theory, and other colleagues. My main motivation was the fact that this idea offered a logical solution to the incompatibility between the theory of relativity and quantum mechanics. I interpreted this incompatibility as the necessity of enlarging the field of Reality by abandoning the classical idea of a single level of Reality.

In 1981, I was intrigued by the idea of a veiled reality of Bernard dEspagnat ${ }^{27}$, but I realized that his solution was not satisfactory, and I therefore decided to publish my findings in an article published in $1982^{28}$ and later, in an elaborated form, in 1985, in the first edition of my book We, the particle and the world ${ }^{29}$.

\footnotetext{
${ }^{27}$ dEspagnat, 1981.

${ }^{28}$ Nicolescu, 1982, pp. 68-77.

${ }^{29}$ Nicolescu, 1985.
} 
In 1998, I was surprised to discover the idea of levels of Reality expressed in a different form, in a book by Werner Heisenberg, Philosophy - The manuscript of 1942. This book had a quite astonishing history: it was written in $1942^{30}$, but it was published in German-only in 1984. I read the French translation of the book in 1998.

The philosophy of Heisenberg is based on two main ideas: the first is the notion of levels of Reality corresponding to different modes of embodying objectivity in terms of the respective process of knowledge, and the second is the gradual erasing of the familiar concept of 3-dimensional space and 1-dimensional time.

For Heisenberg, reality is "the continuous fluctuation of the experience as captured by consciousness. In that sense, it can never be identified to a closed system." 31 By "experience," he understands not only scientific experiments but also the perception of the movement of the soul or of the autonomous truth of symbols. For him, reality is a tissue of connections and of infinite abundance without any ultimate founding ground.

"One can never reach an exact and complete portrait of reality," 32 writes Heisenberg. The incompleteness of physical laws is therefore present in his philosophy, even if he makes no explicit reference to Gödel.

Heisenberg asserts many times, in agreement with Husserl, Heidegger, and Cassirer (whom he knew personally), that one has to suppress any rigid distinction between the Subject and Object. He also writes that one has to renounce the privileged reference to the exteriority of the material world and that the only way to understand the nature of reality is to accept its division in regions and levels. The similarity to my own definition of reality is striking, but the differences are also important. By "region of reality," Heisenberg understands a region characterized by a specific group of relations. His regions of reality are, in fact, strictly equivalent to the levels of organization of contemporary systemic thinking.

His motivation for distinguishing regions and levels of reality is identical to my own motivation: the break between classical and quantum mechanics.

Heisenberg classifies the numerous regions of reality in only three levels, in terms of the different

\footnotetext{
${ }^{30}$ Heisenberg, 1998.

${ }^{31}$ Idem., p. 166.

${ }^{32}$ Ibid., p. 258.
}

proximity between the Object and the Subject ${ }^{33}$. He deduces that the rigid distinction between exact and human sciences has to be abandoned, a fact which sounds very, very transdisciplinary.

Heisenberg's first level of reality corresponds to fields that embody objectivity in an independent way from the knowledge process. Classical physics, electromagnetism, and the two theories of relativity of Einstein belong in this level.

The second level corresponds to fields inseparable from the knowledge process: quantum mechanics, biology, and the sciences of consciousness (like psychoanalysis), for example.

Finally, the third level corresponds to fields created in connection with the knowledge process. He situates there philosophy, art, politics, the metaphors concerning God, the religious experience, and the artistic creative experience.

If the first two levels of Heisenberg totally correspond to my own definition, the third one mixes levels and non-levels (in other words, the zones of non-resistance). The religious experience and the artistic creative experience cannot be assimilated to levels of Reality. They merely correspond to crossing levels in the zone of non-resistance. The absence of resistance and especially the absence of discontinuity in the philosophy of Heisenberg explain the difference between his approach and mine. A rigorous classification of regions in levels cannot be obtained in the absence of discontinuity.

Heisenberg insists on the crucial role of intuition: "Only an intuitive thinking," writes Heisenberg, "could bridge the abyss between old and new concepts; the formal deduction is impotent in realizing this bridge $[. . .]^{34} "$ But Heisenberg did not draw the logical conclusion concerning this impotence of formal thinking; only the non - resistance to our experiences, representations, descriptions, images, or mathematical formalisms can bridge the abyss between two levels. This non-resistance restores the continuity broken by levels.

\subsection{The Logical Axiom: The Included Middle}

The incompleteness of the general laws governing a given level of Reality signifies that, at a given moment of time, one necessarily discovers contradic-

\footnotetext{
${ }^{33}$ bid., p. 372

${ }^{34}$ Idem, p. 261.
} 
tions in the theory describing the respective level: one has to assert $\mathrm{A}$ and non - $\mathrm{A}$ at the same time. This Gödelian feature of the transdisciplinary model of Reality is verified by all the history of science: a theory leads to contradictions and one has to invent a new theory solving these contradictions. It is precisely the way in which we went from classical physics to quantum physics.

However, our habits of mind, scientific or not, are still governed by the classical logic, which does not tolerate contradictions. The classical logic is founded on three axioms:

1. The axiom of identity: $\mathrm{A}$ is $\mathrm{A}$.

2. The axiom of non - contradiction: A is not non - A.

3. The axiom of the excluded middle: There exists no third term T ("T" from "third") which is at the same time $\mathrm{A}$ and non $-\mathrm{A}$.

Knowledge of the coexistence of the quantum world and the macrophysical world and the development of quantum physics have led, on the level of theory and scientific experiment, to pairs of mutually exclusive contradictories (A and non $-\mathrm{A}$ ): wave and corpuscle, continuity and discontinuity, separability and non-separability, local causality and global causality, symmetry and breaking of symmetry, reversibility and irreversibility of time, and so forth.

The intellectual scandal provoked by quantum mechanics precisely consists in the fact that the pairs of contradictories that it generates are actually mutually exclusive when they are analyzed through the interpretive filter of classical logic.

However, the solution is relatively simple: one has to abandon the third axiom of the classical logic, imposing the exclusion of the third, the included middle $\mathrm{T}$.

History will credit Stéphane Lupasco (1900$1988)^{35}$ with having shown that the logic of the included middle is a true logic, mathematically formalized, multivalent (with three values: A, non-A, and $\mathrm{T}$ ) and non-contradictory ${ }^{36}$.

In fact, the logic of the included middle is the very heart of quantum mechanics: it allows us to understand the basic principle of the superposition of "yes" and "no" quantum states.

\footnotetext{
${ }^{35}$ Badescu and Nicolescu (ed.), 1999.

${ }^{36}$ Lupasco, 1951.
}

Heisenberg was fully conscious of the necessity of adopting the logic of the included middle. "There is - writes Heisenberg - a fundamental principle of classical logic which seems to need to be modified: in classical logic, if one assertion has a meaning, one supposes that either this assertion or its negation has to be true. Only one of the sentences "There is a table here" and "There is no table here" is true: tertium non datur, i.e. there is not a third possibility and this is the principle of the excluded middle.[...] In quantum theory, one has to modify this law of the excluded middle. If one protests again any modification of this basic principle, one can immediately argue that this principle is implicated in the ordinary language [...]. Consequently, the description in ordinary language of a logical reasoning which does not apply to this language would mean simply a self-contradiction." 37

Our understanding of the axiom of the included middle - there exists a third term $\mathrm{T}$ which is at the same time A and non-A - is completely clarified once the notion of "levels of Reality", not existing in the works of Lupasco, is introduced.

In order to obtain a clear image of the meaning of the included middle, let us represent the three terms of the new logic - A, non-A, and $\mathrm{T}-$ and the dynamics associated with them by a triangle in which one of the vertices is situated at one level of Reality and the two other vertices at another level of Reality. The included middle is in fact an included third. If one remains at a single level of Reality, all manifestation appears as a struggle between two contradictory elements. The third dynamic, that of the $\mathrm{T}$ - state, is exercised at another level of Reality, where that which appears to be disunited is in fact united, and that which appears contradictory is perceived as non-contradictory.

It is the projection of the $\mathrm{T}$ - state onto the same single level of Reality which produces the appearance of mutually exclusive, antagonistic pairs (A and non - A). A single level of Reality can only create antagonistic oppositions. It is inherently self-destructive if it is completely separated from all the other levels of Reality. A third term which is situated at the same level of Reality as that of the opposites A and non A, cannot accomplish their reconciliation. Of course, this conciliation is only temporary. We necessarily discover contradictions in the theory of the new level when this theory confronts new experimental facts.

\footnotetext{
${ }^{37}$ Heisenberg, 1971, pp. $241-242$;
} 
In other words, the action of the logic of the included middle on the different levels of Reality induces an open structure of the unity of levels of Reality. This structure has considerable consequences for the theory of knowledge because it implies the impossibility of a self-enclosed complete theory. Knowledge is forever open.

The logic of the included middle does not abolish the logic of the excluded middle: it only constrains its sphere of validity. The logic of the excluded middle is certainly valid for relatively simple situations, for example, driving a car on a highway: no one would dream of introducing an included middle in regard to what is permitted and what is prohibited in such circumstances. On the contrary, the logic of the excluded middle is harmful in complex cases, for example, within the economical, social, cultural, religious or political spheres. In such cases it operates like a genuine logic of exclusion: good or evil, right or left, heaven or hell, alive or dead, women or men, rich or poor, whites or blacks. It would be revealing to undertake an analysis of xenophobia, racism, apartheid, anti-semitism, or nationalism in the light of the logic of the excluded middle. It would also be very instructive to examine the speeches of politicians through the filter of that logic.

There is certainly coherence among different levels of Reality, at least in the natural world. In fact, an immense self-consistency - a cosmic bootstrap seems to govern the evolution of the universe, from the infinitely small to the infinitely large, from the infinitely brief to the infinitely long. A flow of information is transmitted in a coherent manner from one level of Reality to another in our physical universe.

The included middle logic is a tool for an integrative process: it allows us to cross two different levels of Reality or of perception and to effectively integrate, not only in thinking but also in our own being, the coherence of the Universe. The use of the included third is a transformative process. But, at that moment, the included third ceases to be an abstract, logical tool: it becomes a living reality touching all the dimensions of our being. This fact is particularly important in education and learning.

\subsection{The Complexity Axiom: The Universal Interdependence}

There are several theories of complexity. Some of them, like the one practiced at the Santa Fe Institute, with the general guidance of Murray Gell -
Mann, Nobel Prize of Physics, are mathematically formalized, while others, like the one of Edgar Morin, widely known in Latin America, are not. In the context of our discussion, what is important to be understood is that the existing theories of complexity do not include neither the notion of levels of Reality nor the notion of zones of non-resistance ${ }^{38}$. However, some of them, like the one of Edgar Morin ${ }^{39}$, are compatible with these notions. It is therefore useful to distinguish between the horizontal complexity, which refers to a single level of reality and vertical complexity, which refers to several levels of Reality. It is also important to note that transversal complexity is different from the vertical, transdisciplinary complexity. Transversal complexity refers to crossing different levels of organization at a single level of Reality.

From a transdisciplinary point of view, complexity is a modern form of the very ancient principle of universal interdependence. This recognition allows us to avoid the current confusion between complexity and complication. The principle of universal interdependence entails the maximum possible simplicity that the human mind could imagine, the simplicity of the interaction of all levels of reality. This simplicity cannot be captured by mathematical language, but only by symbolic language. The mathematical language addresses exclusively to the analytical mind, while symbolic language addresses to the totality of the human being, with its thoughts, feelings and body.

It is interesting to note that the combined action of the ontological, logical and complexity axiom engenders values. Therefore, there is no need to introduce values as a 4 th axiom ${ }^{40}$. The transdisciplinary values are neither objective nor subjective. They result from the Hidden Third, which signifies the interaction of the subjective objectivity of the transdisciplinary Object and the objective subjectivity of the transdisciplinary Subject.

\section{Building a New Spirituality}

"Spirituality" is a completely devaluated word today, in spite of its etymological meaning as "respiration", in an act of communion between us and the cosmos. There is a big spiritual poverty present on

\footnotetext{
${ }^{38}$ Nicolescu, 1996, 1998, 2000.

${ }^{39}$ Morin, 1977, 1980, 1986, 1991, 2001, 2004.

${ }^{40}$ Cicovacki, 2003.
} 
our Earth. It manifests as fear, violence, hate and dogmatism. In a world with more than 10000 religions and religious movements and more than 6000 tongues, how can we dream about mutual understanding and peace? There is an obvious need for a new spirituality, conciliating technoscience and wisdom. Of course, there are already several spiritualities, present on our Earth from centuries and even millennia. One might ask: why is there a need for a new spirituality if we have them all, here and now?

Before answering to this question, we must face a preliminary question: is a Big Picture still possible in our post-modern times? Radical relativism answers in a negative way to this question. However its arguments are not solid and logical. They are in fact very poor and obviously linked to the totalitarian aspect of the political and philosophical correctness expressed by the slogan "anything goes". For radical relativists, after the death of God, the death of Man, the end of ideologies, the end of History (and, perhaps, tomorrow, the end of science and the end of religion) a Big Picture is no more possible. For transdisciplinarity, a Big Picture is not only possible but also vitally necessary, even if it will never be formulated as a closed theory. We are happy that the well-known art critic Suzi Gablik, in her book Has Modernism Failed? ${ }^{41}$, joined recently our point of view. The last chapter of her book is entitled Transdisciplinarity-Integralism and the New Ethics. For her, the essential intellectual change of the last two decades is precisely transdisciplinarity. This change was anticipated by the big quantum physicist Wolfgang Pauli (1900-1958), Nobel Prize of Physics, who wrote fifty years ago: "Facing the rigorous division, from the 17 th century, of human spirit in isolated disciplines, I consider the aim of transgressing their opposition [...] as the explicit or implicit myth of our present times." 42

The first motivation for a new spirituality is technoscience, with its associated fabulous economic power, which is simply incompatible with present spiritualities. It drives a hugely irrational force of efficiency for efficiency sake: everything which can be done will be done, for the worst or the best. The second motivation for a new spirituality is the difficulty

\footnotetext{
${ }^{41}$ Gablik, 2004. The first edition was published in 1984.

${ }^{42}$ Pauli, 1999, chapter "Science and Western Thinking", p. 178. This chapter was first published in 1955, in Europa Erbe und Aufgabe, Internazionaler Gelehrtehkongress, Meinz.
}

of the dialogue between different spiritualities, which often appear as antagonistic, as we can testify in our everyday life. The new phenomenon of a planetary terrorism is not foreign to these two problems.

In simple words, we need to find a spiritual dimension of democracy. Transdisciplinarity can help with this important advancement of democracy, through its basic notions of "transcultural" and "transreligious" 43 .

The transcultural designates the opening of all cultures to that which cuts across them and transcends them, while the transreligious designates the opening of all religions to that which cuts across them and transcends them ${ }^{44}$. This does not mean the emergence of a unique planetary culture and of a unique planetary religion, but of a new transcultural and transreligious attitude. The old principle "unity in diversity and diversity from unity" is embodied in transdisciplinarity.

Through the transcultural, which leads to the transreligious, the spiritual poverty could be eradicated and therefore render the war of civilizations obsolete. The transcultural and transreligious attitude is not simply a utopian project - it is engraved in the very depths of our being.

This evolution of mentalities could be achieved only if we perform the unification of Homo religious with Homo economicus.

Homo religiosus probably existed from the beginnings of the human species, at the moment when the human being tried to understand the meaning of his life. The sacred is his natural realm. He tried to capture the unseen from his observation of the visible world. His language is that of the imaginary, trying to penetrate higher levels of Reality - parables, symbols, myths, legends, revelation.

Homo economicus is a creation of modernity. He believes only in what is seen, observed, measured. The profane is his natural realm. His language is that of just one level of Reality, accessible through the analytic mind-hard and soft sciences, technology, theories and ideologies, mathematics, informatics.

Transdisciplinary methodology is able to identify the common germ of homo religiosus and of homo economicus-called homo sui transcendentalis in my Manifesto of Transdisciplinarity ${ }^{45}$. This identification could be done by taking into account the new

\footnotetext{
${ }^{43}$ Nicolescu, 1996.

${ }^{44}$ Nicolescu, 1996.

${ }^{45}$ Nicolescu, 1996.
} 
relation established by transdisciplinarity between Object and Subject.

In Pr - Modernity the Subject was immersed in the Object. Everything was trace, signature of a higher meaning. The world of the pre-modern human being was magical (see Figure 1).
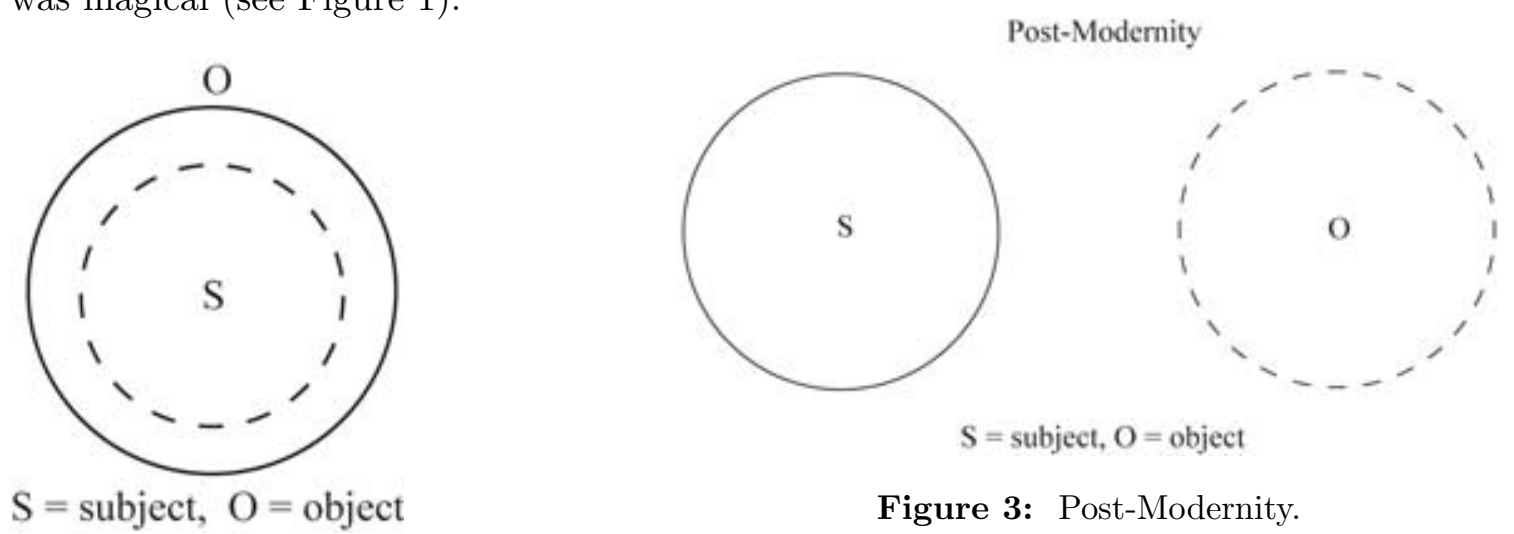

Figure 3: Post-Modernity.

Figure 1: Pr-Modernity.

In Modernity, Subject and Object were totally separated (see Figure 2) by a radical epistemological cut, allowing in such a way the development of modern science. The Object was just there, in order to be known, deciphered, dominated, and transformed.

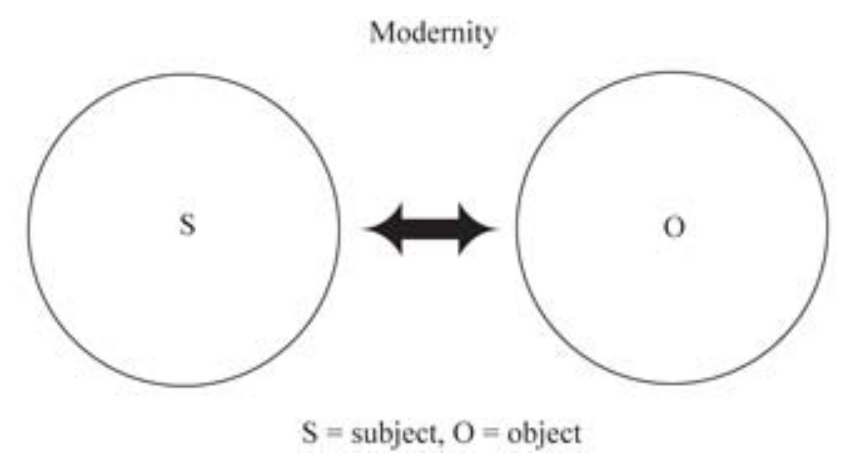

Figure 2: Modernity.

In Post-Modernity the roles of the Subject and Object are changed in comparison with Modernity and are reversed in comparison with Pre-Modernity: the Object, still considered as being outside the Subject, is nevertheless a social construction. It is not really "there". In looks more like an emanation of the Subject.

Transdisciplinarity leads to a new understanding of the relation between Subject and Object, which is illustrated in Figure 4:

The Subject and the Object are, like in Modernity, separated but they are unified by their immersion 
in the Hidden Third, whose ray of action is infinite. The transdisciplinary Object and its levels, the transdisciplinary Subject and its levels and the Hidden Third define the Transdisciplinary Reality or Trans-Reality ${ }^{46}$ (see Figure 5)

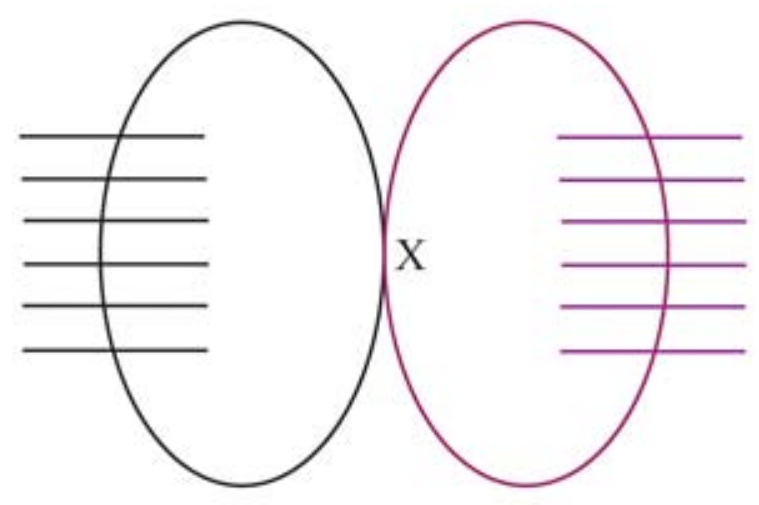

Figure 5: Hidden Third.

"What is Reality?" - asks Charles Sanders Peirce (1839-1914), a great philosopher, logician, mathematician of the beginning of the 20th century ${ }^{47}$. He tells us that maybe there is nothing at all which corresponds to Reality. It may be just a working assumption in our desperate tentative in knowing. But if there is a Reality - tells us Peirce - it has to consist in the fact that the world lives, moves and has in itself a logic of events, which corresponds to our reason. Peirce's view on Reality totally corresponds to the transdisciplinary view on Reality.

The unified theory of levels of Reality is crucial in building sustainable development and sustainable futures. The considerations made till now in these matters are based upon reductionist and binary thinking: everything is reduced to society, economy and environment. The individual level of Reality, the spiritual level of Reality and the cosmic level of Reality are completely ignored. Sustainable futures, so necessary for our survival, can only be based on a unified theory of levels of Reality. We are part of the ordered movement of Reality. Our freedom consists in entering into the movement or perturbing it. Reality depends on us. Reality is plastic. We can respond to the movement or impose our will of power and domination. Our responsibility is to build sustainable futures in agreement with the overall movement of Reality.

\footnotetext{
${ }^{46}$ Nicolescu, 2009.

${ }^{47}$ Peirce, 1976, vol. IV, p. 383-384.
}

\section{References}

Léo Apostel, Guy Berger, Asa Briggs and Guy Michaud (ed.), L'interdisciplinarité-Problémes d'enseignement et de recherche, Centre pour la Recherche et l'Innovation dans l'Enseignement, Organisation de Coopération et de développement conomique, Paris, 1972.

Horia Badescu and Basarab Nicolescu (ed.), Stéphane Lupasco - L'homme et l'oeuvre, Le Rocher, Monaco, 1999. Translation in Portuguese : Stéphane Lupasco - O Homem e a Obra, TRIOM et University of São Paulo, São Paulo, 2001, translation by Lucia Pereira de Souza.

Michel Camus, Thierry Magnin, Basarab Nicolescu and Karen-Claire Voss, "Levels of Representation and Levels of Reality: Towards an Ontology of Science", in Niels H. Gregersen; Michael W.S. Parsons and Christoph Wassermann (ed.), The Concept of Nature in Science and Theology (part II), Genve, Éditions Labor et Fides, 1998, pp. 94-103.

The Charter of Transdisciplinarity (in French, Spanish, English, Portuguese, Turkish, Italian, Arab and Romanian): http://basarab.nicolescu.perso.sfr.fr/ciret/

Predrag Cicovacki, "Transdisciplinarity as an Interactive Method : A Critical Reflection on the Three Pillars of Transdisciplinarity", communication at the congress The Unifying Aspects of Cultures, Vienna, November 7-9, 2003.

Vincent Descombes, Le complément du sujet, Gallimard, Paris, 2004.

d'Espagnat, Bernard. A la recherche du réel, GauthierVillars, Paris, 1981.

Pierre Duguet, "L'approche des problèmes", in Léo Apostel et al. (1972).

Paulo Freire, Pedagogy of the Oppressed, The Seabury Press, New York, 1968.

Suzi Gablik, Has Modernism failed ?, Thames§Hudson, New York, 2004.

Galileo Galilei, Dialogue sur les deux grands systémes du monde, Seuil, Paris, 1992, translated from the Italian by René Fréreux with the collaboration of Franois de Gandt, pp. 128-130; Dialogue on the Great World Systems, University of Chicago Press, Chicago, 1956, with an introduction by Giorgio de Santillana.

Michael Gibbons, Camille Limoges, Helga Nowotny, Simon Schwartzman, Peter Scott and Martin Trow (ed.). The New Production of Knowledge, London, Thousand Oaks, New Delhi, SAGE, 1994. 
"Guerre et paix antre les science : disciplinarité et transdisciplinarité", Revue du MAUSS, No 10, Paris, 1997.

Werner Heisenberg, Philosophie - Le manuscrit de 1942 Paris, Seuil, 1998, translation from German and introduction by Catherine Chevalley German original edition: Ordnung der Wirklichkeit, R. Piper GmbH $\S \mathrm{KG}, \mathrm{Mu}^{-}$ nich, 1989. Published first in W. Blum, H. P. Dürr, and H. Rechenberg (Ed.), W. Heisenberg Gesammelte Werke, Vol. C-I : Physik und Erkenntnis, 1927-1955, R. Piper GmbH $\S$ KG, Munich, 1984, pp. 218-306. A translation in English of this book can be found on the Internet page http://werner-heisenberg.unh.edu/t-OdW english.htm\#seg01

Edmund Husserl, Mé ditations cartésiennes, Vrin, Paris, 1966. Translated form the German by Gabrielle Peiffer and Emmanuel Levinas.

Erich Jantsch, a. "Vers l'interdisciplinarité et la transdisciplinarité dans l'enseignement et l'innovation", in Léo Apostel et al. (1972).

b. Technological Planning and Social Futures, Cassell/Associated Bussiness Programmes, London, 1972.

André Lichnerowicz, "Mathématique et transdisciplinarité", in Léo Apostel et al. (1972).

Stéphane Lupasco, Le principe d'antagonisme et la logique de l'énergie - Prolégoménes à une science de la contradiction, Hermann \& Cie, Coll. "Actualités scientifiques et industrielles", no 1133, Paris, 1951 ; 2nd ed. Le Rocher, Monaco, 1987, foreword by Basarab Nicolescu.

Edgar Morin, La méthode I- La nature de la nature, Paris, Seuil, 1977.

Seuil, 1980 .

La méthode II- La vie de la vie, Paris,

La méthode III -La connaissance de la connaissance, Paris, Seuil, 1986.

La méthode IV- Les idées, leur habitat, leur vie, leurs moeurs, leur organisation, Paris, Seuil, 1991.

Seven Complex Lessons in Education, Paris, UNESCO, 1999. Translated from the French by Nidra Poller.

La méthode V- L'humanité de l'humanité, Paris, Seuil, 2001.

2004.

La méthode VI Ethique, Paris, Seuil,

Ernest Nagel and James R. Newman, Gödel's Proof, New
York University Press, New York, 1958.

Basarab Nicolescu, "Sociologie et mécanique quantique", 3e Milnaire, no 1, Paris, March-April 1982.

Nous, la particule et le monde, Le Mail, Paris, 1985. 2nd edition, Le Rocher, Monaco, "Transdisciplinarité" Series, 2002.

"Science as Testimony", in Proceedings of the Symposium Science and the Boundaries of Knowlege : the Prologue of Our Cultural Past, organised by UNESCO in collaboration with the Cini Foundatio(Venice, March 3-7, 1986), Paris, UNESCO, 1986, pp. 9-30.

Science, Meaning and Evolution - The Cosmology of Jacob Boehme, with selected texts by Jacob Boehme, New York, Parabola Books, 1991. Translated from the French by Rob Baker.

Foreword by Joscelyn Godwin, afterword by Antoine Faivre.

a. La transdisciplinarité, manifeste, Monaco, Le Rocher, "Transdisciplinarité" Series, 1996. English translation: Manifesto of Transdisciplinarity. New York: SUNY Press, 2002, translation from the French by Karen-Claire Voss. Translation in Portuguese: O Manifesto da Transdisciplinaridade, Triom, São Paulo, 1999, translation by Lucia Pereira de Souza; 2nd edition: 2001.

b. "Levels of Complexity and Levels of Reality", in Bernard Pullman (ed.), The Emergence of Complexity in Mathematics, Physics, Chemistry, and Biology. Vatican City, Pontificia Academia Scientiarum, 1996, pp. 393-417. Distributed by Princeton University Press. Proceedings of the Plenary Session of the Pontifical Academy of Sciences, 27-31 October 1992, Casina Pio IV, Vatican.

-a. "The Transdisciplinary Evolution of the University, Condition for Sustainable Development", Rencontres Transdisciplinaires No 12, February 1998.

http://perso.club-internet.fr/nicol/ciret/bulletin/b12 /b12.c8.htm.

-b. "Gödelian Aspects of Nature and Knowledge", in Gabriel Altmann and Walter A. Koch (ed.), Systems- New Paradigms for the Human Sciences, Berlin - New York, Walter de Gruyter, 1998, pp. 385-403.

"Hylemorphism, Quantum Physics and Levels of Reality", in Demetra Sfendoni - Mentzou (ed.), Aristotle and Contemporary Science, New York, Peter Lang, 2000, Vol. I, pp. 173-184. Introduction by Hilary Putnam. 
"Toward a Methodological Foundation of the Dialogue Between the Technoscientific and Spiritual Cultures", in Liubava Moreva (ed.), Differentiation and Integration of Worldviews, Eidos, Sankt Petersburg, 2004

"Toward Transdisciplinary Education", The Journal for Transdisciplinary Research in Southern Africa, North-West University, Wanderbijlpark, South Africa, Vol. 1, $\mathrm{n}^{\circ}$ 1, December 2005, p. 5-15.

"Transdisciplinarity- past, present and future", in Moving Worldviews - Reshaping sciences, policies and practices for endogenous sustainable development, COMPAS Editions, Holland, 2006, edited by Bertus Haverkort and Coen Reijntjes, p. 142-166.

"Transdisciplinarity as a Methodological Framework for Going beyond the Science - Religion Debate", Transdisciplinarity in Science and Religion, $\mathrm{n}^{\circ}$ 2, 2007, Curtea Veche Publ., Bucharest, p. 35-60.

a. "Spiritual Dimension of Democracy: Utopia or Necessity?", in Andrei Marga, Theodor Bercheim and Jan Sadlak (Ed.), Living in Truth, Cluj University Press, Babes-Bolyai University, Cluj - Napoca, 2008, p. 509-516.

b. "The Idea of Levels of Reality- Its Relevance for Non-Reduction and Personhood", Transdisciplinarity in Science and Religion, no 4, 2008, Curtea Veche Publ., Bucharest, p. 11-25 .

Canada, 2009.

Quést-ce que la réalité?, Liber, Montréal,

Basarab Nicolescu (ed.), Transdisciplinarity-Theory and Practice, Hampton Press, Cresskill, New Jersey, 2008.

Helga Nowotny, "The Potential of Transdisciplinarity": http://www.interdisciplines.org

/interdisciplinaritypapers/5

Wolfgang Pauli, Physique moderne et philosophie, Albin Michel, Paris, 1999, translated from the German by Claude Maillard.

Jean Piaget, "Lépistémologie des relations interdisciplinaires", in Léo Apostel et al. (1972).

Charles Sanders Peirce, Collected Papers of Charles Sanders Peirce, 8 volumes, Charles Hartshorne, Paul Weiss, and Arthur Burks (Ed.), Harvard University Press, Cambridge, Massachusetts, 1931-1958.

Charles Sanders Peirce, Selected Writings (Values in a Universe of Chance), Dover Publications, New York, 1966 , edited with an introduction and notes by Philip P. Wiener.

Charles Sanders Peirce, The New Elements of Mathemat- ics, 4 volumes, C. Eisele (Ed.), Mouton Humanities Press, The Hague, 1976.

Julie Thompson Klein, Walter Grossenbacher-Mansuy, Rudolf Häberli, Alain Bill, Ronald W. Scholz and Myrtha Welti (ed.). Transdisciplinarity: Joint Problem Solving among Science, Technology, and Society-An Effective Way for Managing Complexity, Basel-Boston-Berlin, Birkhäuser Verlag, 2001.

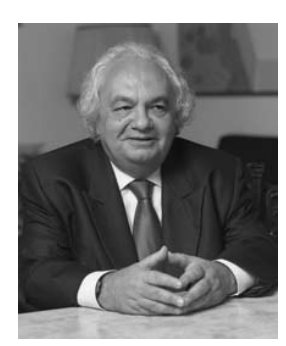

Basarab Nicolescu is a theoretical physicist in elementary particle physics at CNRS, France and professor of philosophy at the Babes-Bolyai University, Cluj-Napoca, Romania. He is member of the Romanian Academy and president-founder of the International Center for Transdisciplinary Research and Studies (CIRET). Basarab Nicolescu is founder and director of the Transdisciplinarity series, Rocher, Monaco, of the Romanians in Paris series, Oxus, Paris and of the Science and Religion and Science, Spirituality, Society Series, Curtea Veche, Bucharest. His books include: Manifesto of Transdisciplinarity, State University of New York (SUNY) Press, New York, 2002; Nous, la particule et le monde, E. M. E. InterCommunications, Brussels, 2012 (3rd edition); Science, Meaning and Evolution - The Cosmology of Jacob Boehme, Parabola Books, New York, 1991. He edited Transdisciplinarity - Theory and Practice, Hampton Press, Cresskill, New Jersey, 2008. Forthcoming: Science, Culture and Spirituality From Modernity to Cosmodernity, State University of New York (SUNY) Press, New York (to be published). A complete bio-bibliography of Basarab Nicolescu can be found on the page http://www.basarab-nicolescu.fr/index.php

Copyright (c) 2010 by the author. This is an open access article distributed under the Creative Commons Attribution License (https://creativecommons.org/licenses/ by/4.0/), which permits unrestricted use, distribution, and reproduction in any medium, provided the original work is properly cited. 